\title{
A luta pela educação na Baixada Fluminense-RJ: o contexto de expansão do Ensino Superior
}

\author{
Renan Arjona de Souza ${ }^{1}$ \\ Nádia Maria Pereira de Souza ${ }^{2}$
}

\begin{abstract}
Resumo
Este estudo busca de forma descritiva caracterizar a região da Baixada Fluminense, no Estado do Rio de Janeiro, tendo em vista alguns aspectos geográficos, históricos, políticos e sociais, assim como as principais políticas educacionais voltadas para essa região no período delimitado entre os anos de 1990 a 2009 . Essa caracterização proporcionou o entendimento de um ambiente político-educacional de luta por mais investimentos em educação, oriunda dos movimentos sociais organizados locais. Esses movimentos foram importantes para o reconhecimento dessa região como um dos lugares propícios para receber um Campus Universitário Federal, fruto do Programa de Expansão e Interiorização do Ensino Superior (2005), uma política educacional do governo Luís Inácio Lula da Silva (2003-2010). Essa caracterização ressalta ainda, em suas considerações finais, a importância das lutas dos movimentos sociais organizados por mais investimentos em educação e os benefícios de um lócus de formação em regiões carentes de políticas socioeducacionais.
\end{abstract}

Palavras-Chave: Baixada Fluminense. Educação Superior. Movimentos Sociais.

\begin{abstract}
This study aims to characterize the region of Baixada Fluminense, in the State of Rio de Janeiro, considering some geographic, historical, political and social aspects; As well as the main educational policies aimed at this region during the period from 1990 to 2009. This characterization provided the understanding of a politicaleducational environment of struggle for more investments in education, coming from local organized social movements. These movements were important for the recognition of this region as one of the places chosen to receive a Federal University Campus, as a result of the Expansion and Interiorization Program of Higher Education (2005), an educational policy of the Government Luis Inácio Lula da Silva (2003-2010. This characterization emphasizes in its final considerations the importance of the struggles for the social movements organized by more investments in education and the benefits of a locus of formation in regions lacking socioeducational policies.
\end{abstract}

Keywords: Baixada Fluminense. Higher Education. Social Movements.

\section{Introdução}

Historicamente, no Brasil, o crescimento desenfreado das metrópoles intensificou as desigualdades, produzindo fenômenos como a "favelização" e periferias urbanas. Essas regiões convivem com problemas de infraestrutura, baixa escolarização e renda. A região conhecida como Baixada Fluminense é uma região do estado do Rio de Janeiro, e, assim

\footnotetext{
${ }^{1}$ Administrador na Universidade Federal Rural do Rio de Janeiro (UFRRJ). Coordenador do Núcleo de Graduação do Campus Nova Iguaçu da UFRRJ. renanarjona@gmail.com

2 Professora do Departamento de Teoria e Planejamento de Ensino (Instituto de Educação) da Universidade Federal Rural do Rio de Janeiro (UFRRJ).nmpsouza@uol.com.br
}

COLÓQUIO - Revista do Desenvolvimento Regional - Faccat - Taquara/RS - v. 15, n. 1, jan./jun. 2018 
como em outras regiões do país com as mesmas características, torna-se alvo de políticas educacionais cujos objetivos são tentar reduzir as desigualdades sociais.

Dessa forma, este artigo busca caracterizar esta região tendo em vista alguns aspectos geográficos, históricos, políticos e sociais, assim como as principais políticas educacionais voltadas para essa região no período delimitado entre os anos de 1990 a 2009. Essa caracterização proporcionou o entendimento de um ambiente político-educacional de luta por mais investimentos em educação, oriundo dos movimentos sociais organizados nessa região.

Tal ambiente colaborou para o governo federal considerar essa uma das regiões escolhidas para receber um campus universitário, no programa de Expansão e Interiorização do Ensino Superior, criada no governo do Presidente Luís Inácio Lula da Silva, em 2003.

\section{Caracterização da Baixada Fluminense do estado do Rio de Janeiro}

A região da Baixada Fluminense, no estado do Rio de Janeiro, é conhecida hoje pela sua área plana localizada entre a Baía de Guanabara, Serra do Mar e a Serra do Mendanha/Madureira. A região apresenta uma história de ocupação relacionada com os meios de transporte e de acesso de pessoas e mercadorias - inicialmente as vias fluviais e, posteriormente, a via férrea, e, já na segunda metade do século $X X$, a rodovia -, e sua proximidade, por mais de dois séculos, da então capital do país, e, atualmente, do Estado. De acordo com Simões (2007), características naturais, como opções fluviais para escoar a produção agrícola, foram um fator importante, mas a fundação da cidade do Rio de Janeiro, em 1565, possibilitou a efetiva ocupação do território ao redor da Baía de Guanabara.

$\mathrm{Na}$ primeira metade do século XX, Nova Iguaçu - que englobava o que hoje consideramos como Baixada Fluminense - era o maior produtor de cítricos do país, mas a Segunda Guerra Mundial afetou a exportação de laranjas, gerando grave e definitiva crise. A construção da rodovia Presidente Dutra favoreceu o processo de industrialização e facilitou o acesso à capital, provocando o aumento populacional e a intensa ocupação do território, com o loteamento das áreas de laranjais e a construção de conjuntos habitacionais, sendo o trem o principal meio de transporte da população local, servida por várias estações ferroviárias (UFRRJ, 2005). Assim, verifica-se que a transformação dessa região numa área urbana periférica, intimamente ligada à cidade do Rio de Janeiro, ocorreu já na segunda 
metade do século XX. Esse processo de contínua reestruturação socioespacial do Rio de Janeiro precisa ser entendido em função das transformações econômicas e políticas pelas quais o Brasil passou nesse século.

Segundo Simões (2007), o modelo econômico brasileiro aponta para uma concentração espacial das atividades econômicas e da população da cidade do Rio de Janeiro, gerando uma pressão maior e uma disputa mais intensa pelo uso do solo urbano na cidade, acirrando a questão habitacional e a dos transportes públicos. Iniciam-se, então, dois processos simultâneos, uma centralização cada vez maior de atividades econômicas ligadas ao terciário, no centro da cidade, e uma descentralização tanto das atividades industriais como da população, gerando uma nova onda de expansão da mancha urbana da cidade, que chegará à Baixada Fluminense.

A Baixada Fluminense integra a mesorregião metropolitana do estado do Rio de Janeiro, juntamente com a capital e a Grande Niterói, caracterizada por alta densidade populacional. Na Figura 1, a seguir, é possível verificar a mancha urbana característica da região, que se estende até o município de Japeri. Os municípios de Magé e Seropédica, por suas características rurais, estão numa área mais distante desta configuração.

\section{Figura 1 - Baixada Fluminense 2015 - mancha urbana}

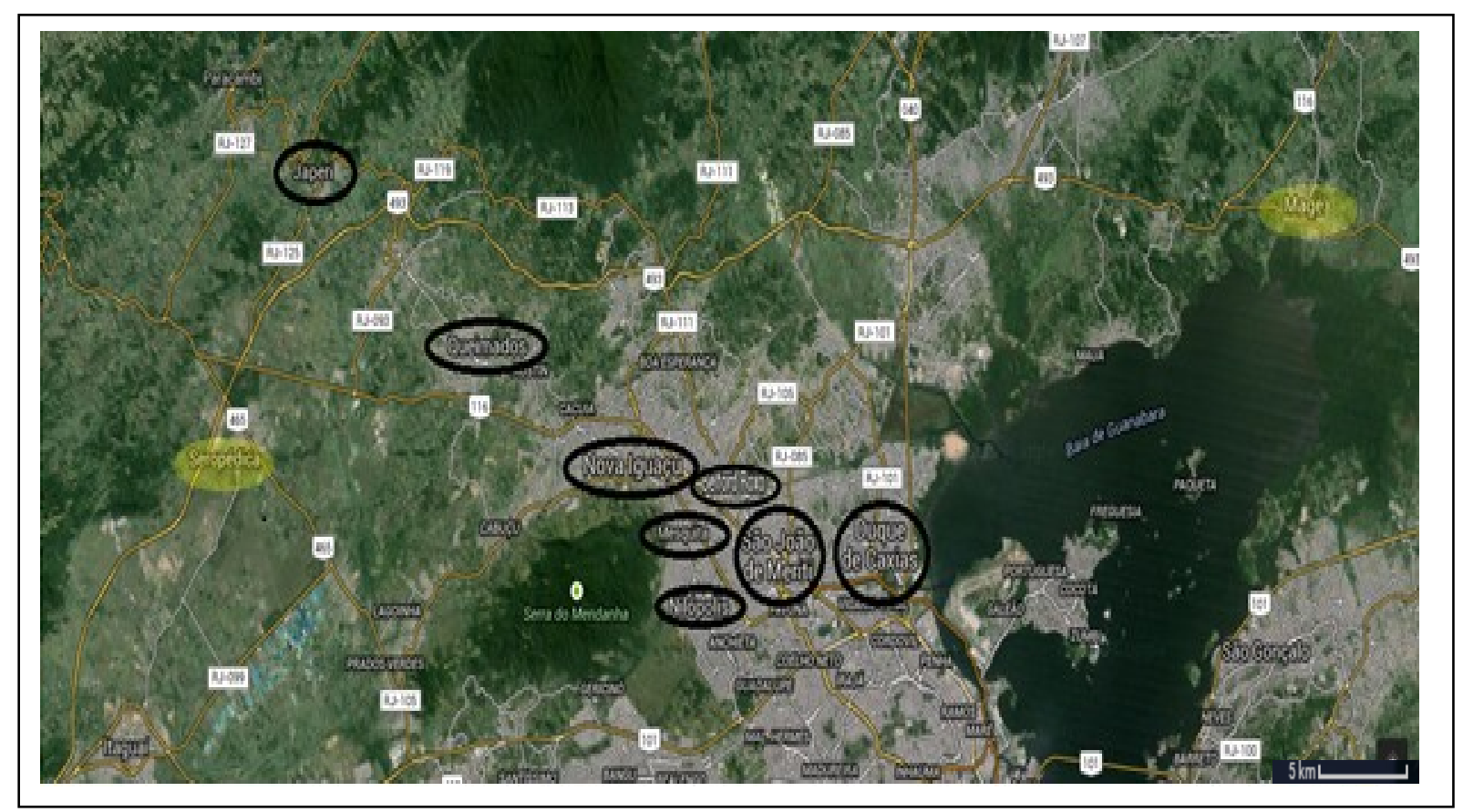

Fonte: Google Maps (2015) - Adaptado pelo autor. 
A delimitação política da Baixada Fluminense é definida de formas diferentes por diferentes autores, porque a proximidade física entre as localidades não eliminou as diferenças que se constituíram ao longo da história. Simões (2007) destaca, porém, um consenso que aponta Nova Iguaçu e Duque de Caxias como núcleos, e os municípios de Belford Roxo, São João de Meriti, Nilópolis, Mesquita, Queimados e Japeri, que ficam ao norte da cidade do Rio de Janeiro, como componentes dessa região. Magé, Guapimirim, que ficam a leste, e Itaguaí, Paracambi e Seropédica, que ficam a oeste, nem sempre são considerados integrantes da Baixada Fluminense em um sentido estrito.

Os municípios da Baixada Fluminense constituem - juntamente com o centro - uma área densa chamada metrópole. Nessas áreas,

a proximidade entre os núcleos urbanos torna difícil sua individualização, e os
fluxos dos moradores através dos territórios municipais é permanente; deve-se
pensar em uma nova divisão de tarefas entre as prefeituras e os governos
estaduais para que não ocorram superposições ou lacunas no atendimento à
população (SIMÔES, 2007, p. 274).

Então, neste estudo, vamos nos referir à Baixada Fluminense da forma mais utilizada e considerada por Simões (2007) como um consenso em muitas pesquisas, restringindo-a aos oito municípios: Duque de Caxias, Nova Iguaçu, Belford Roxo, São João de Meriti, Nilópolis, Mesquita, Queimados e Japeri. É interessante destacar que esses municípios até a década de 1940 constituíam-se num único: Nova Iguaçu. Segundo o Projeto Acadêmico do Instituto Multidisciplinar, os desmembramentos do território se iniciam na década de 1940 e se estendem até o final dos anos 1990.

A partir da década de 1940, Nova Iguaçu passa por um significativo processo de desmembramento a partir da emancipação de importantes distritos: Duque de Caxias e São João de Meriti, em 1943, e Nilópolis, em 1947. Na década de 1990, o município tem sua área e população bastante reduzidas com o desmembramento e as emancipações de Belford Roxo e Queimados (1990), Japeri (1991) e Mesquita (1999) (UFRRJ, 2005, p. 6).

Como pode ser visualizado no mapa abaixo (Figura 2), as emancipações ocorridas na Baixada Fluminense atingem também Magé e Itaguaí, com as emancipações de Guapimirim (1990) e Seropédica (1995), respectivamente. 
Figura 2 - Emancipações na Baixada Fluminense

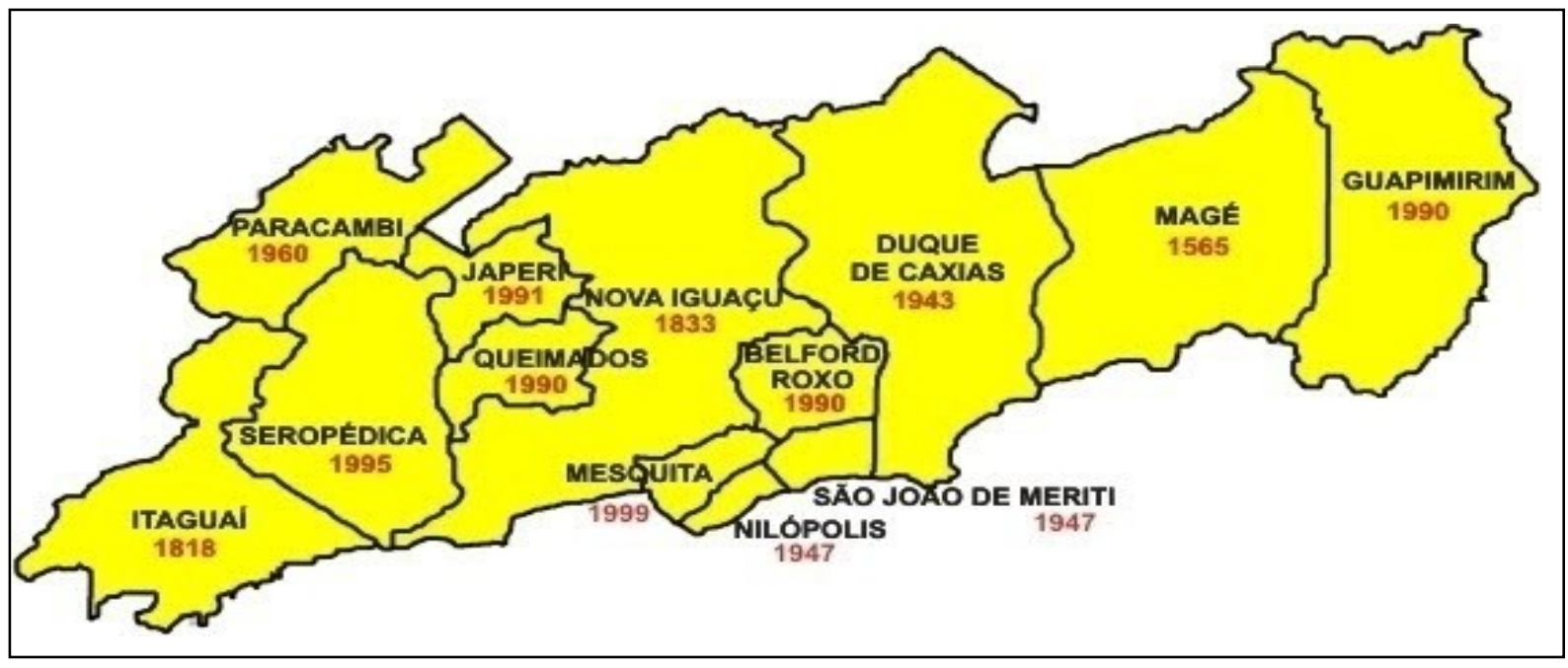

Fonte: Panoramio (2016).

A partir da redemocratização do país, acirradas disputas políticas e eleitorais destacaram a importância estratégica dessa região para o controle do poder no âmbito estadual. Segundo Simões (2007, p. 274), os processos de emancipação ocorridos nesta época contribuíram para melhorar a qualidade de vida de todos os envolvidos, possibilitando uma ligação mais orgânica, ainda que de caráter não classista, com a população local, apesar de muitos retrocessos nas relações políticas e na estrutura de poder.

Em relação à estrutura de poder na região, cabe ressaltar uma infeliz característica política que ainda hoje persiste,

que é a eleição para vereadores de políticos dos bairros populares, que não possuem expressão no plano municipal. Em geral são praticantes do fisiologismo, negociando apoio aos prefeitos em troca de benesses [...]. A diferença é o nível de violência que existe nas disputas entre estes políticos, vários vereadores, secretários municipais e assessores da Baixada foram mortos ou sofreram atentados durante seus mandatos (SIMÕES, 2007, p. 252).

Talvez esta característica seja reforçada pelos baixos índices sociais registrados nessa região quando comparados com a capital fluminense ou outras regiões do estado do Rio de Janeiro, como é destacado a seguir: 
[a Baixada Fluminense] ao longo da sua história, caracterizou-se pela deficiência infraestrutural, populações carentes e abandono pelo poder público e por trazer em seu bojo contrastes sociais, culturais, políticos e econômicos próprios a uma sociedade de classe de padrão periférico e inserção subordinada como a brasileira (SILVA, 2010, p. 89).

A região da Baixada Fluminense tem cerca de $20 \%$ da população do estado do Rio de Janeiro $^{3}$. Apesar de um grande percentual da população ainda ocupar postos de trabalho na cidade do Rio de Janeiro, a região possui um dos maiores centros comerciais do estado e concentração de algumas indústrias, como a de cosméticos, por exemplo.

Entretanto, apesar do elevado desempenho econômico, os baixos índices sociais e educacionais são uma marca negativa da Baixada Fluminense. Os índices sociais mostravam, no final do Século XX, que a região estava distante das taxas aceitáveis de desenvolvimento humano. E, nesse caso, seria um erro associar desenvolvimento econômico com desenvolvimento social numa relação única, pois, mesmo com os melhores índices de desenvolvimento econômico, podemos notar na Tabela 1 que Nova Iguaçu e Duque de Caxias não lideravam o ranking IDH da região.

Numa análise do Índice de Desenvolvimento Humano (IDH) da região, comparando os anos de 1991 e 2000, podemos ver, a seguir, o avanço em todos os municípios no período, e, ao mesmo tempo, o atraso, quando comparados à capital.

Tabela 1 - Ranking IDH da Baixada Fluminense 1991 e 2000

\begin{tabular}{lcccr|rrrr}
\hline \multirow{2}{*}{ Município } & \multicolumn{4}{c|}{1991} & \multicolumn{4}{c}{$\mathbf{2 0 0 0}$} \\
\cline { 2 - 10 } & $\begin{array}{c}\text { IDHM } \\
\mathbf{1 9 9 1}\end{array}$ & $\begin{array}{c}\text { IDHM } \\
\text { renda }\end{array}$ & $\begin{array}{c}\text { IDHM } \\
\text { longevid }\end{array}$ & $\begin{array}{c}\text { IDHM } \\
\text { educaç }\end{array}$ & $\begin{array}{c}\text { IDHM } \\
\mathbf{2 0 0 0}\end{array}$ & $\begin{array}{c}\text { IDHM } \\
\text { renda }\end{array}$ & $\begin{array}{c}\text { IDHM } \\
\text { longevid }\end{array}$ & $\begin{array}{c}\text { IDHM } \\
\text { educaç }\end{array}$ \\
\hline Rio de Janeiro & 0,639 & 0,757 & 0,714 & 0,483 & 0,716 & 0,803 & 0,754 & 0,607 \\
\hline Nilópolis & 0,565 & 0,636 & 0,685 & 0,414 & 0,656 & 0,694 & 0,724 & 0,563 \\
\hline Mesquita & 0,543 & 0,610 & 0,687 & 0,383 & 0,634 & 0,672 & 0,742 & 0,512 \\
\hline São João de Meriti & 0,514 & 0,598 & 0,670 & 0,338 & 0,620 & 0,655 & 0,744 & 0,489 \\
\hline Duque de Caxias & 0,506 & 0,604 & 0,670 & 0,320 & 0,601 & 0,652 & 0,726 & 0,458 \\
\hline Nova Iguaçu & 0,502 & 0,595 & 0,675 & 0,315 & 0,597 & 0,656 & 0,717 & 0,453 \\
\hline Belford Roxo & 0,468 & 0,566 & 0,630 & 0,288 & 0,570 & 0,620 & 0,717 & 0,417 \\
\hline Queimados & 0,448 & 0,553 & 0,630 & 0,258 & 0,550 & 0,619 & 0,690 & 0,390 \\
\hline Japeri & 0,419 & 0,543 & 0,626 & 0,217 & 0,529 & 0,597 & 0,694 & 0,357 \\
\hline
\end{tabular}

Fonte: Elaborado pelo autor, com base em PNUD (2016).

\footnotetext{
${ }^{3}$ 2.549.389 habitantes na Baixada Fluminense e 12.773 .138 habitantes no Estado do Rio de Janeiro. COLÓQUIO - Revista do Desenvolvimento Regional - Faccat - Taquara/RS - v. 15, n. 1, jan./jun. 2018
} 
Diante desse quadro, que mostrava através de indicadores sociais e educacionais a necessidade de mais investimentos na região, além de sua alta densidade populacional e importância econômica, a Baixada Fluminense foi escolhida para receber o primeiro campus universitário dentro do programa de expansão das IFES, no ano de 2005. A cidade a sediar o empreendimento seria Nova Iguaçu, e a instituição, a Universidade Federal Rural do Rio de Janeiro (UFRRJ).

\section{Políticas educacionais e suas influências na Baixada Fluminense entre os anos de 1990 a 2009}

Ao abordarmos as políticas educacionais nacionais, há de se considerar as complexas variáveis políticas externas e internas. Ainda assim, outro aspecto importante a considerar é a história da luta pela educação pública no Brasil, que, podemos afirmar, seguiu a própria história da luta pelos direitos da cidadania brasileira.

Não é pretensão deste artigo resgatar a história de lutas pela educação pública no Brasil, que é ampla e riquíssima, mas, sim, destacar um aspecto de influência nas políticas educacionais, em que, segundo Janete Azevedo (2004), a sociedade envolvida pelo movimento da globalização não se forja independentemente das características históricas e estruturais dos países em que se implantam, ou seja,

\footnotetext{
as novas configurações sociais não surgem do abstrato, pois são fruto da ação humana e, como tal, têm história socialmente construída. Sendo assim, são passíveis de mudanças por sua ressignificação em função dos interesses internamente dominantes, ou de transformações resultantes da luta dos grupos dominados contra a própria dominação, processos esses que ocorrem no contexto das relações sociais engendradas em cada sociedade (AZEVEDO, 2004, p. XIV).
}

Nesse contexto, o momento político da Baixada Fluminense, por volta da redemocratização do Brasil e nos anos de 1990, revelava anseios por melhores condições de vida para a região e um ambiente político-partidário que parecia não atender às demandas da população. Silva (2010) destaca, por exemplo, que, naquela época, era comum o desenvolvimento de uma prática de cooptação das lideranças do movimento social emergente na região por parte do governador do estado do Rio de Janeiro da época, Leonel Brizola, ainda com resquícios do clientelismo político, marca histórica da política local. 
Por outro lado, com influência da Igreja Católica, os movimentos sociais mostraram a sua força junto à população por meio de um trabalho de organização e de conscientização política. Dessa forma, eles foram o principal instrumento de organização na Baixada Fluminense a pressionar o estado a ser mais receptivo às necessidades da população nos anos seguintes.

Através das dioceses de Nova Iguaçu e Duque de Caxias, a atuação da Igreja se caracterizava, primeiramente, por oferecer amparo aos movimentos que se colocassem a favor do povo, por meio das Comunidades Eclesiais de Base (CEBs). Posteriormente, por meio da organização de pequenos grupos fundados na paróquia ou na capela, onde o padre responsável tratava de organizar os seus fiéis em torno de algum problema da comunidade. Este movimento foi definido como:

\footnotetext{
Uma práxis educativa forjada, sobretudo, a partir da Teologia da Libertação e de Paulo Freire e adensada no conflito hegemônico no interior da igreja e da sociedade civil. Uma práxis de formação política popular militante que, inicialmente, quase que ingênua e populista, vai lentamente adensando a autoconsciência de educador político popular na linha gramsciana (SILVA, 2007, p. 51).
}

Dessa forma, além da rede de CEBs, Silva (2010) destaca também que se derivou na Baixada Fluminense um poderoso movimento social que tem no Movimento Amigos de Bairro (MAB), no Movimento de União de Bairros de Duque de Caxias (MUB) e na Associação de Bairros e Moradores de São João de Meriti ( $A B M)$ sua face mais visível. O MAB atuou nas políticas de educação de forma limitada e na esteira dos convênios, como, por exemplo, com a Fundação Educar (Projeto Educar) e com o MEC (Pré-escolar), até início dos anos 1990. Convém registrar a atuação de outros movimentos organizados e mobilizados em favor da educação, mais especificamente em Nova Iguaçu, como a União Iguaçuana de Estudantes Secundaristas (UIES), o Clube das Mães e o Sindicato Estadual dos Profissionais da Educação (SEPE).

Mesmo diante de movimentos populares organizados e de atuação junto aos poderes municipais concernentes às políticas educacionais na Baixada Fluminense, percebem-se esses movimentos insuficientes para a transformação social do trabalho de educação popular até então desenvolvido. Surgia, então, a dificuldade de manutenção de lideranças e sujeitos autônomos dentro desse espaço político. 


\begin{abstract}
A Federação das Associações de Moradores de Nova Iguaçu, por exemplo, que, desde meados dos anos 70, luta pelo estabelecimento de mecanismos de negociações diretas com o executivo municipal, de "audiências públicas", como forma de barrar a prática clientelista estabelecida nas relações políticas locais, vê frustrada essa sua tentativa com a retomada da prática de cooptação política de lideranças de origem popular (SILVA, 2007, p. 52).
\end{abstract}

Assim, a diocese de Nova Iguaçu, ainda sob a liderança de Dom Adriano Hypólito, decide investir numa formação política popular para além da mera conscientização. Motivada pela pergunta estratégica: "Que Baixada Fluminense queremos daqui a 10 anos?", a diocese desenvolve, a partir de 1995, um projeto de formação social destinado às suas lideranças, com os objetivos de estimular nos agentes sociais a consciência dos direitos do povo, reforçando a sua participação efetiva na transformação social; e propiciar oportunidades de confrontar suas experiências, aprofundando os conhecimentos necessários ao enfrentamento das situações novas (SILVA, 2007, p. 53).

Destaca-se, nesse período, o envolvimento de algumas entidades sindicais e organizações não governamentais nas mobilizações populares da região. O SEPE/Nova Iguaçu se envolveu na luta pelas eleições para diretores na rede pública e na luta pela preservação dos CIEPs, além de tentar participar dos Conselhos Municipais de Educação. Segundo Silva (2010, p. 104), entre 1997 e 1998, na ocasião da criação dos Conselhos Municipais de Educação e do FUNDEF, o núcleo do SEPE/Nova Iguaçu empenhou-se por intervir neles, sobretudo no Conselho Municipal do FUNDEF. Porém, apesar da pressão pela transparência das contas públicas e da luta pela autonomia do Conselho, os esforços foram em vão, pois os sucessivos governos municipais (1997-2004) esvaziaram o Conselho Municipal do FUNDEF em Nova Iguaçu.

Outra luta popular relevante pela educação pública aconteceu em torno do Centro Federal de Educação Tecnológica (CEFET/NI), pois as obras iniciadas em 1988 estavam paralisadas, em 1992, por questões financeiras, e, em 1995, por questões judiciais. Em 1999, as obras foram retomadas, após atuação do Fórum das Entidades e de algumas filiadas do $M A B$, e realização de atividades como abaixo-assinado, debates em escolas e abraço simbólico ao prédio do CEFET.

$\mathrm{Na}$ esteira deste movimento social popular, desdobram-se várias iniciativas de educação política popular, como a criação do Centro Sociopolítico (CSp), em março de 2001; 
a Escola de Formação Política, a partir de 2003, que se consolidou como uma das grandes bandeiras locais referentes à educação, uma universidade pública. Em contrapartida, apesar dos esforços de alguns movimentos sociais para superar o clientelismo, no Brasil da "abertura lenta e gradual", esse velho fenômeno político se fez presente no cotidiano das políticas públicas, sobretudo nas políticas de educação, e veio se transmutando até os dias atuais.

Em Nova Iguaçu, por exemplo, uma política educacional realizada neste contexto foi - Programa Municipal de Bolsas de Estudo (PROMUBE), pautado na bolsa "Salário Educação". Esse programa financiava estudantes do ensino fundamental em escolas particulares, na falta de vagas na rede pública, porém “[...] não apresenta(va) qualquer condicionamento ao repasse, nem obrigações do Poder Público Municipal quanto à solução para a falta de vagas na rede pública" (SILVA, 2010, p. 148). Observa-se na tese de doutorado do pesquisador Percival Tavares da Silva que "[...] que o estudo do PROMUBE revelou ser mais uma forma de burlar a Lei para repasse de recursos da educação pública às instituições privadas de ensino. Apropriação privada de corte moderno, [...] mas, sobretudo, clientelista e patrimonialista" (2010, p. 210).

No bojo das políticas educacionais que afetaram diretamente a Baixada Fluminense nesse período, cabe destacar as profundas mudanças que começaram a ocorrer nas formas de ingresso para ocupação de vagas e a adoção (valorização e estímulo) simultânea de políticas de ações afirmativas. A Universidade do Estado do Rio de Janeiro foi pioneira ao autorizar que pretos, pardos e indígenas (PPI) autodeclarados solicitassem suas vagas por meio de um sistema de reserva de vagas, distribuídas na seguinte proporção: $20 \%$ para negros, $20 \%$ para alunos de escola pública e $5 \%$ para portadores de necessidades especiais.

Segundo Bezerra (2011), para os ingressantes do ano 2003 nessa universidade estadual, foram realizadas duas modalidades de vestibular: o Sistema de Acompanhamento de Desempenho dos Estudantes do Ensino Médio (Sade), para a reserva de vagas, e o chamado vestibular estadual, sem cotas, ambos com graus de dificuldade similares. Estudos como o de Bezerra (2011), por exemplo, abordam o advento das políticas de ingresso por cotas nas universidades públicas. Estas apontam para a ampliação das oportunidades a estudantes alijados de uma educação pública de qualidade, pois, com raras exceções, 
estudantes de escolas públicas vivem cotidianamente com problemas de falta de professores e de um ambiente de formação adequado.

Em termos de poder público municipal, apesar da meta instituída no PNE (20012010), nenhum dos oito municípios em estudo neste trabalho estabeleceu o seu Plano Municipal de Educação durante a vigência deste PNE. Os Planos Municipais desses municípios vieram a se consolidar somente nos anos de 2014, em Duque de Caxias, e de 2015 nos demais municípios.

Dada esta relativa falta de políticas educacionais locais consistentes na Baixada Fluminense, o município, frequentemente, vivencia debates sobre a violência, quase sempre relacionada à pobreza e a problemas sociais mal resolvidos. Então, no ano de 2005, o recémempossado prefeito de Nova Iguaçu, Lindberg Farias, resgatou um dos compromissos centrais a que se propunha a sua gestão, que era estabelecer estratégias de criar uma rede de prevenção à violência. Elas dizem respeito a um leque de ações a serem ampliadas na cidade e também nas unidades escolares.

Segundo Souza e Silva e Goulart (2011), o ano de 2006 foi importante para a Baixada Fluminense em função da realização do Fórum Mundial da Educação em Nova Iguaçu, ocasião em que o projeto Bairro Escola foi apresentado. Vale destacar em termos de políticas educacionais municipais a experiência de Nova Iguaçu com esse programa, que pretendia a construção de um espaço escolar da educação fundamental integrado à comunidade, partindo do princípio da intersetorialidade, modelo de financiamento que integrava recursos de diferentes instâncias governamentais e não governamentais.

Dessa forma, o programa Bairro Escola destinava-se à formação continuada dos professores, universitários bolsistas, monitores, agentes culturais, agentes de esporte e lazer, profissionais de saúde da família, assistentes sociais, alunos da rede pública de ensino e seus familiares. Todos esses atores estavam envolvidos na aplicação de um programa que almejava dobrar o tempo de permanência dos alunos na escola, como solução diante da incapacidade orçamentária do município, que não teria condições de suportar um investimento desse tamanho.

Nesse contexto, essa política educacional municipal tinha clareza da importância dos universitários para sua viabilização e, em contrapartida, da sua necessidade para eles, que 
tinham na experiência do Bairro Escola uma oportunidade de receber uma bolsa auxílio para custearem os estudos. Esses objetivos estavam bem definidos, como descritos a seguir.

\begin{abstract}
Ao transformar universitários em agentes de mudanças, tornamos a universidade parte relevante do processo educativo e não somente um objetivo isolado na trajetória do estudante de Nova Iguaçu em sua busca de conhecimento e qualificação profissional. A universidade, nesse processo de interlocução e ação comum, passa a ser algo concreto, palpável, independentemente da cor, raça, classe econômica e opção religiosa do estudante. Historicamente palco e origem de grandes reivindicações em defesa dos direitos do cidadão, a instituição passa a assumir, através dos seus representantes, o desafio de transformar a realidade para além dos seus muros (SOUZA; SILVA; GOULART, 2011, p. 79).
\end{abstract}

O Projeto Pré-Vestibular Popular, criado pela prefeitura de Nova Iguaçu em parceria com a Universidade Federal do Rio de Janeiro (UFRJ), a partir do ano de 2006, também se constituiu numa política do governo municipal que visava melhorar as condições de formação dos estudantes da cidade. Entre estes, especialmente dos oriundos da escola pública, de modo que suas chances nos vestibulares das universidades públicas fossem otimizadas.

Dessa forma, dada a constatação de iniciativas isoladas de políticas educacionais locais consistentes no país, somente a partir do Plano de Desenvolvimento da Educação (PDE), no ano de 2007, o Ministério da Educação (MEC) consegue promover um regime de colaboração entre os entes federados. Isto foi feito por meio de incentivos às iniciativas municipais de colaboração com as metas nacionais, quando se colocou à disposição dos estados, municípios e distrito federal instrumentos de avaliação e de implementação de políticas, visando à melhoria da qualidade da educação, sobretudo da educação básica pública.

O Plano de Metas Compromisso Todos pela Educação, um programa estratégico do PDE, instituído pelo Decreto 6.094, de 24 de abril de 2007, inaugurou a proposta do regime de colaboração, conciliando a atuação dos entes federados, respeitada sua autonomia, envolvendo primordialmente a decisão política, a ação técnica e o atendimento da demanda educacional, visando à melhoria dos indicadores educacionais. Sendo um compromisso fundado em vinte e oito diretrizes e consubstanciado em um plano de metas concretas e efetivas, compartilha competências políticas, técnicas e financeiras para a execução de programas de manutenção e desenvolvimento da educação básica. A partir da adesão ao 
Plano de Metas, os estados, os municípios e o distrito federal passaram à elaboração de seus respectivos Planos de Ações Articuladas (PAR).

O PDE - e seus derivados - aprovado pelo governo Lula, surgiu à margem e independente do Plano Nacional de Educação (2001-2010). Ao compor um sistema nacional de formação dos profissionais da educação, mediante a ação reguladora da CAPES, o PDE resgata a lógica da pós-graduação para as escolas, submetendo a educação básica e seus profissionais à lógica produtivista que hoje caracteriza a pós-graduação em nosso país. Freitas (2007, p. 1222) afirma que uma política de formação deve fundar-se em condições que permitam a participação ativa dos professores e de suas entidades, tratando igualmente as bases da educação escolar, visando sua transformação para a construção de uma nova qualidade da educação básica, orientada pelas necessidades sociais da formação de nossa infância e da juventude.

Nesse sentido, no campo das contradições das políticas públicas, as quais, muitas vezes, promovem soluções fáceis, ágeis e de "menor custo" para as iniciativas no âmbito da educação e particularmente da formação,

\footnotetext{
a construção de diretrizes que induzam os estados e municípios a essa transformação ultrapassa aquelas definidas no Compromisso Todos pela Educação, do Plano de Desenvolvimento da Educação. Supõe outros interlocutores, os educadores, os estudantes, os pais, e os movimentos sociais, alijados do processo de construção das políticas atuais e do novo Plano de Desenvolvimento da Educação (FREITAS, 2007, p. 1222).
}

Então, ainda no ano de 2007, a fim de (re) organizar um sistema de formação docente para a educação básica, foi criada a Diretoria de Educação Básica Presencial (DEB), quando a Lei 11.502, de 11 de julho de 2007, conferiu à Coordenação de Aperfeiçoamento de Pessoal de Nível Superior (CAPES) as atribuições de induzir e fomentar a formação inicial e continuada de profissionais da educação básica, estimulando a valorização do magistério em todos os níveis e modalidades de ensino.

De acordo com o Relatório de Gestão do PRODOCÊNCIA (MEC/CAPES/DEB, 2012), a visão política dos integrantes da DEB sobre a relevância social da carreira do magistério da educação básica conduziu a estratégia de fomentar a integração entre programas de pósgraduação, cursos de formação de professores e escolas públicas de educação básica. Assim, 
a Capes incentiva as instituições de educação superior a reconhecerem nas escolas públicas um espaço de produção e de apropriação de conhecimento, tornando-as, simultaneamente, partícipes e beneficiárias dos estudos e dos projetos desenvolvidos.

Nesse contexto, com base em lançamento de editais, o DEB propõe que as instituições de educação superior gerem uma dinâmica de aprimoramento recíproco e contínuo, com impactos positivos na educação brasileira, respeitando a autonomia das universidades e com responsabilidade compartilhada.

Assim, ganharam força os projetos institucionais nas instituições públicas de ensino superior, como o Programa de Consolidação das Licenciaturas (Prodocência), o Programa Conexões de Saberes e o Programa Institucional de Bolsa de Iniciação à Docência (PIBID). Através desses programas, instituições como UFRJ, UNIRIO, UFF e UERJ, por exemplo, mais próximas da região da Baixada Fluminense, promoveram atividades de impacto educacional importante para as redes públicas desta região, dentro de um contexto político e legal de fortalecimento de um sistema de formação docente para a educação básica.

A UFRRJ também foi protagonista, por meio desses três programas institucionais, atuando na Baixada Fluminense, principalmente através do recém-inaugurado Campus Nova Iguaçu. Esta universidade, inclusive, promoveu a reformulação dos Programas Pedagógicos dos Cursos (PPCs) a partir do ano de 2008. Essa reformulação dos PPCs da UFRRJ foi promovida pelo "Programa Institucional de Formação de Professores para Educação Básica da UFRRJ", que propôs um conjunto de ações, políticas institucionais e propostas pedagógicas, consolidando a formação de professores a partir da premissa de que a formação docente precisa ser valorizada e trabalhada desde os momentos iniciais da formação do licenciando ${ }^{4}$.

O governo federal conclamou as IFES, em geral, a instituírem o ENEM como componente dos seus vestibulares no ano de 2009, mas somente em 2012 a Lei 12.711 determinou que as universidades federais destinassem $50 \%$ de suas matrículas para estudantes autodeclarados negros, pardos, indígenas. Nos editais de seleção das universidades públicas federais mais próximas da região da Baixada Fluminense, pode-se verificar que a UNIRIO, desde 2001, utiliza o ENEM como componente de seleção, tornando-

\footnotetext{
${ }^{4}$ UFRRJ - Deliberação CEPE no 138/2008.

COLÓQUIO - Revista do Desenvolvimento Regional - Faccat - Taquara/RS - v. 15, n. 1, jan./jun. 2018
} 
se pioneira nessa prática, e instituiu reserva de vagas a professores da rede pública a partir do ano de 2010. A UFF instituiu políticas afirmativas no ano de 2008 para estudantes oriundos de escolas públicas e professores da rede. E a UFRRJ instituiu o ENEM como componente de seleção para as turmas ingressantes no ano de 2010, e, em 2011, incluiu a reserva de vagas para estudantes de escola pública e professores da rede.

Desse modo, até o ano de 2009, delimitação temporal deste estudo, pouco se pode relatar em nível de marco educacional nesses oito municípios. Isso revela que as políticas de formação docente em questão ficaram aquém do ideal, com sucessivas mudanças que não estabeleceram um padrão minimamente consistente de preparação deste docente para fazer face aos problemas educacionais.

Toda a luta pelos movimentos sociais desta região foi importante para que a Baixada Fluminense fosse agraciada com um campus universitário público federal, pois essa luta propagou as deficiências de formação docente que existem na rede de educação básica. Além da demanda de professores para atuarem na educação básica, pois em muitos lugares ainda existe essa carência, falta também qualificação para os docentes em atividade nas redes estaduais e municipais, como pode ser visto na tabela a seguir.

Tabela 2 - Professores da Educação Básica com curso superior - 2007

\begin{tabular}{lrrrrrr}
\hline \multicolumn{1}{c}{ MUNICÍPIOS } & \multicolumn{2}{c}{ Com Superior } & \multicolumn{2}{c}{ Com Licenciatura } & \multicolumn{2}{c}{ Sem Licenciatura } \\
\hline Nilópolis & $78,5 \%$ & 1.692 & $71,9 \%$ & 1.550 & $6,6 \%$ & 142 \\
Duque de Caxias & $78,3 \%$ & 5.455 & $71,9 \%$ & 5.004 & $6,5 \%$ & 451 \\
São João de Meriti & $74,1 \%$ & 2.327 & $68,3 \%$ & 2.145 & $5,8 \%$ & 182 \\
Nova Iguaçu & $73,8 \%$ & 4.673 & $67,4 \%$ & 4.271 & $6,3 \%$ & 402 \\
Queimados & $70,8 \%$ & 822 & $63,9 \%$ & 742 & $6,9 \%$ & 80 \\
Belford Roxo & $67,0 \%$ & 2.408 & $62,6 \%$ & 2.249 & $4,4 \%$ & 159 \\
Mesquita & $66,8 \%$ & 921 & $61,9 \%$ & 853 & $4,9 \%$ & 68 \\
Japeri & $54,2 \%$ & 535 & $51,1 \%$ & 504 & $3,1 \%$ & 31 \\
\hline
\end{tabular}

Fonte: Todos pela educação. Observatório PNE. Elaborada pelo autor.

A Tabela 2 revela as diferenças entre os próprios municípios da região, mas parece que, de forma geral, ainda existe a necessidade de avanços no tocante à qualificação dos professores. O município com melhor quadro de professores em termos de qualificação é Nilópolis, e, ainda assim, conta com 21,5\% de professores na educação básica sem formação 
em nível superior. No tocante à qualificação, a formação inicial é importante, já que é base de sustentação de um processo formativo continuado, capaz de articular essa formação inicial com as experiências profissionais, assim como é a condição fundamental para o exercício profissional.

\section{Considerações finais}

$\mathrm{Na}$ Baixada Fluminense-RJ, em função da necessidade latente e da luta pelos movimentos sociais organizados, tornou-se impactante a política pública federal de expansão do ensino superior para essa região, ao se implantar um campus universitário para fins de promoção de mais oportunidades de formação.

Os cursos de graduação, através do seu papel formador, podem contribuir para o desenvolvimento de uma localidade. E já existem referências e estudos de caso de municípios que avançaram em índices educacionais pautados no investimento na formação dos professores da rede básica. Esse processo não é um fim em si mesmo, mas um meio de contribuir para a melhoria da qualidade do ensino na escola.

\footnotetext{
Assumir tal responsabilidade implica também exigir das instituições formadoras o repensar de seus processos de formação, atualizando-os e colocando-os em sintonia com as exigências do desenvolvimento científico e tecnológico e com as demandas da sociedade, já que investir na formação de professores é essencial para que haja transformações na escola (ZAINKO, 2010, p. 121).
}

E, “[...] para atender a essa necessidade de mais professores, será necessário investir na ampliação da oferta de vagas nos cursos de licenciatura de boa qualidade, isto é, nas universidades públicas" (SAVIANI, 2011, p. 18).

O contexto político partidário é permeado pelo discurso em favor das minorias, porém, influenciado pela lógica neoliberal presente no ensino superior brasileiro, esse discurso não se traduz necessariamente em políticas a favor de todos aqueles que ingressam numa faculdade.

As universidades, historicamente, voltaram o espaço acadêmico para as elites econômicas e intelectuais, com o ensino tradicionalmente oferecido a poucos privilegiados. Dentro dessa perspectiva, a maior oferta de cursos de ensino superior voltada para a 
formação de professores deve ser vista com atenção, a fim de que o discurso da democratização do acesso não se transforme na elitização de um modo ainda mais perverso, através da "inclusão marginal" 5 .

Portanto, ressalta-se uma política de valorização do magistério como profissão, com o sentido de projeto de vida e de futuro, no sentido de reforçar um espaço construído pelos próprios educadores, no qual se discutem ideias sobre ensino e aprendizagem e se elaboram perspectivas comuns sobre os desafios da formação.

Através desses espaços,

reforça-se um sentimento de pertença e de identidade profissional que é essencial para que os professores se apropriem dos processos de mudança e os transformem em práticas concretas de intervenção. É esta reflexão coletiva que dá sentido ao desenvolvimento profissional dos professores (NÓVOA, 2009, p. 42).

Concluindo, as mobilizações sociais e influências de políticas educacionais na Baixada Fluminense foram base para a conquista de um espaço de formação em nível superior. As IFES são referências no ensino superior no Brasil e se constituem como polos fundamentais para viabilizar tais políticas.

Nesse contexto, este lócus de formação auxilia a região a combater os baixos índices socioeducacionais e apresentar melhores condições para uma formação de professores com qualidade social referenciada.

\section{Referências}

AZEVEDO, Janete M. L. A educação como política pública. 3. ed. Campinas: Autores Associados, 2004. (Coleção polêmicas do nosso tempo; v. 56).

BEZERRA, Teresa Olinda Caminha. A política pública de cotas em universidades, desempenho acadêmico e inclusão social. SBIJOURNAL, n. 9, 2011.

\footnotetext{
${ }^{5}$ Rigorosamente falando não existe exclusão: existe contradição, existem vítimas de processos sociais, políticos e econômicos excludentes; existe o conflito pelo qual a vítima dos processos excludentes proclama seu inconformismo, seu mal-estar e sua reivindicação corrosiva. Estas reações, por não se tratarem de exclusão, não se dão fora dos sistemas econômicos e dos sistemas de poder. Elas constituem o imponderável de tais sistemas, fazem parte deles, ainda que os negando (MARTINS, 1997, p. 14).
}

COLÓQUIO - Revista do Desenvolvimento Regional - Faccat - Taquara/RS - v. 15, n. 1, jan./jun. 2018 
BRASIL. Decreto presidencial no 6.094, de 24 de abril de 2007 - Dispõe sobre a implementação do Plano de Metas Compromisso Todos pela Educação, pela União Federal, em regime de colaboração com Municípios, Distrito Federal e Estados, e a participação das famílias e da comunidade, mediante programas e ações de assistência técnica e financeira, visando a mobilização social pela melhoria da qualidade da educação básica. Diário Oficial da União, Brasília, DF, 25 abr. 2007. Seção 1, p. 5.

FREITAS, Helena Costa Lopes de. A (nova) política de formação de professores: a prioridade postergada. Educação \& Sociedade, v. 28, n. 100, p. 1203-1230, 2007.

GOOGLE MAPS. 2005. Disponível em: <https://www.google.com.br/maps>. Acesso em: 15 jul. 2016.

MARTINS, José de Souza. A exclusão e a nova desigualdade. São Paulo: Paulus. (1997)

NÓVOA, Antônio. Imagens do futuro presente. Lisboa: EDUCA, 2009.

PANORAMIO - Google Maps. Disponível em: <www.panoramio.com/photo/74366169>. Acesso em: 15 jul. 2016.

PROGRAMA DAS NAÇÕES UNIDAS PARA O DESENVOLVIMENTO - PNUD. Ranking Índice de Desenvolvimento Humano dos Municípios (IDHM). Disponível em:

<http://www.pnud.org.br/atlas/ranking/Ranking-IDHM-Municipios-2000.aspx>. Acesso em: 4 abr. 2015.

UFRRJ. Projeto Político Pedagógico do Instituto Multidisciplinar da UFRRJ (PPP-IM). 2005. Deliberação CONSU n. 4 de 30 de março de 2006. Disponível em:

<http://institucional.ufrrj.br/soc/>. Acesso em: 15 abr. 2016.

. Programa Institucional de Formação de Professores para a Educação Básica.

Deliberação CEPE n. 138 de 11 de dezembro de 2008. Disponível em:

<http://r1.ufrrj.br/graduacao/arquivos/docs_academico/delib_cepe_138_2008.pdf>. Acesso em: 20 mar. 2016.

SAVIANI, Dermeval. Formação de professores no Brasil: dilemas e perspectivas. Poíesis Pedagógica, v. 9, n. 1, p. 7-19, 2011.

SILVA, Percival Tavares. A práxis da formação política das classes populares. Revista de Educação Pública, Cuiabá, 2007, p. 49-67.

SILVA, Percival Tavares. Bolsas de estudo no ensino fundamental privado, entre a universalidade de direito à educação e o clientelismo na educação: o caso de Nova Iguaçu/ RJ. 327 f. Tese (Doutorado em Educação) - Universidade de São Paulo, São Paulo, 2010. 
SIMÕES, Manoel Ricardo. A cidade estilhaçada: reestruturação econômica e emancipações municipais na Baixada Fluminense. 292 f. Tese (Doutorado em Geografia) - Universidade Federal Fluminense, Rio de Janeiro. 2007.

SOUZA E SILVA, Jaílson; GOULART, Maria Antônia. Bairro Escola: a experiência da educação integral em Nova Iguaçu. Rio de Janeiro, Observatório das Favelas, 2011.

TODOS PELA EDUCAÇÃO. Observatório PNE. Disponível em:

<http://www.observatoriodopne.org.br/>. Acesso em: 11 dez. 2015.

ZAINKO, Maria Amélia Sabbag. Políticas de formação de professores na universidade pública: uma análise de necessidades, entre o local e o global. Educar em Revista, n. 37, 2010. 